\title{
Circulating Extracellular Vesicle MicroRNA as Diagnostic Biomarkers in Early Colorectal Cancer-A Review
}

\author{
Brendan J. Desmond ${ }^{1, * \mathbb{D}}$, Elizabeth R. Dennett ${ }^{1,2}$ and Kirsty M. Danielson ${ }^{1}$ (D) \\ 1 Department of Surgery \& Anaesthesia, University of Otago Wellington, 23 Mein St., Wellington 6021, \\ New Zealand; liz.dennett@otago.ac.nz (E.R.D.); kirsty.danielson@otago.ac.nz (K.M.D.) \\ 2 Department of General Surgery, Wellington Hospital, 23 Mein St., Wellington 6021, New Zealand \\ * Correspondence: Brendan.desmond@otago.ac.nz; Tel.: +64-212963975
}

Received: 12 November 2019; Accepted: 13 December 2019; Published: 23 December 2019

\begin{abstract}
Colorectal cancer (CRC) is one of the most common malignancies in the developed world, with global deaths expected to double in the next decade. Disease stage at diagnosis is the single greatest prognostic indicator for long-term survival. Unfortunately, early stage CRC is often asymptomatic and diagnosis frequently occurs at an advanced stage, where long-term survival can be as low as $14 \%$. Circulating microRNAs encapsulated in extracellular vesicles (EVs) have recently come to prominence as novel diagnostic markers for cancer. EV-miRNAs are dysregulated in the circulation of CRC patients compared to healthy controls, and several specific miRNA candidates have been posited as diagnostic markers, including miR-21, miR-23a, miR-1246, and miR-92a. This review outlines the current landscape of EV-miRNAs as potential diagnostic markers for CRC, with a specific focus on those able to detect early stage disease.
\end{abstract}

Keywords: exosome; microvesicle; miRNA; liquid biopsy; non-coding RNA

\section{Introduction}

Colorectal cancer (CRC) is the third most frequently diagnosed cancer globally, with over a million patients diagnosed and half a million deaths annually [1]. By 2030, the worldwide incidence of CRC is expected to increase by up to $60 \%$, resulting in 1.1 million deaths [2]. Early diagnosis of CRC is key for reducing CRC mortality; five-year survival for stage I and II disease is approximately $90 \%$, which drops to $14 \%$ for stage IV disease [3]. Current screening and diagnostic strategies for CRC include faecal occult blood testing (FOBT), faecal immunochemical testing (FIT), flexible sigmoidoscopy, and colonoscopy. While these strategies work to reduce CRC mortality, issues with their use include limited sensitivity in early stage disease (faecal tests), invasiveness, and high resource burden [4]. The development of novel, sensitive, and minimally invasive diagnostic strategies for early stage CRC is essential to the continued reduction of CRC mortality.

MicroRNA (miRNA) are short, non-coding regulatory RNA molecules that are stable in the circulation, due in part to their encapsulation in extracellular vesicles (EVs). EV-miRNA are overexpressed in numerous cancers and have recently become the focus of an extensive amount of work aiming to identify novel biomarkers of disease [5-7]. This review will outline the current landscape of EV-miRNAs as potential diagnostic biomarkers for early stage CRC, as well as some of the current challenges to their clinical translation.

\section{CRC Diagnosis and Screening}

$\mathrm{CRC}$ is diagnosed following a symptomatic presentation, due to screening programmes, or as an incidental finding during investigations performed for unrelated reasons. Symptoms upon presentation 
can include weight loss, change in bowel habit, and perirectal bleeding; however, patients are often asymptomatic at early stages of disease [8]. Colonoscopy is the gold standard investigative and diagnostic tool in CRC. Unfortunately, extensive pre-procedure preparation, risk of complication, and high healthcare costs hinder its universal application for population-based screening in many countries [9].

Stool-based population screening programmes (FOBT and FIT) have been adopted in at least twelve countries [10]. FOBT is a guaiac-based test that detects occult blood in the stool, whereas FIT utilises immunoassays specific for human haemoglobin [11]. FIT is preferable over FOBT for population-based screening due to its higher sensitivity ( $79 \%$ vs. $71.2 \%$ ) and comparable specificity (94\% vs. 93.6\%) for CRC detection [12-15]. A major limitation of faecal-based tests as a screening tool are their limited sensitivity for detection of adenomas and early stage CRC. FIT has been shown to have a higher percentage of false-negative results in detection of carcinoma in situ and T1 lesions when compared to more advanced stages, with a sensitivity as low as $66.7 \%$ for these early lesions [4].

While the adoption of population-based screening is a positive step toward reducing CRC-related mortality, screening uptake is not universal and is generally only available between the ages of 50-75 [10]. A considerable number of patients with CRC are either not eligible or do not participate in screening, likely only being diagnosed once the disease is more advanced [16]. Uptake rates of stool-based screening have been reported at $41-57 \%$, and research suggests that there is a patient preference for blood tests compared to faecal-based screening [17-19]. A study by Osborne and colleagues found that $78 \%$ of participants would prefer to give a blood sample for CRC screening over a stool-based test [19].

\section{Liquid Biopsy Biomarkers for CRC}

The concept of a "liquid biopsy" stems from the discovery that cancer cells secrete molecules into the circulation that contain signature markers of their cell of origin $[20,21]$. The advantages of blood-based screening include minimal invasiveness, repeatability, and possible improved uptake compared to stool-based methods. Currently, no liquid biopsy markers are routinely used for screening or diagnosis of CRC. Carcinoembryonic antigen (CEA) is commonly used to monitor for recurrence; however, issues with sensitivity and specificity negate its use in diagnosis or screening [22].

The development of liquid biopsy biomarkers with higher sensitivity for early detection of CRC has the potential to dramatically improve rates of CRC-related mortality. Novel diagnostic and screening strategies may be used either in conjunction with, or as a replacement for, current stool-based screening programmes. Recently, various molecules have been identified as potential liquid biopsy markers. These include circulating tumour cells that originate from primary or metastatic sites, circulating cell-free tumour DNA (cfDNA), as well as miRNA, which can be free in the circulation or encapsulated in EVs [23,24].

Circulating cfDNA has been found to be significantly higher in CRC patients compared to healthy controls [25-27]. One form of cfDNA, methylated Septin9, has been approved by the United States (US) Food and Drug Administration as a PCR-based test for CRC screening. While early case-control studies of this test reported a $70 \%$ sensitivity and $90 \%$ specificity for CRC detection, testing in an asymptomatic cohort found only $35 \%$ sensitivity with $91 \%$ specificity for the detection of stage I CRC. This would hinder its viability for population-based screening for early stage cancers [28-30].

A significant amount of ongoing research is focused on the rapidly developing field of EVs. EVs are stable in the circulation and under various storage conditions [31,32], and reflect both the unique profile of the constituents of their cell of origin, as well as protecting these constituents in the circulation by encapsulation within a membrane. There has been increasing interest in examining the contents of these EVs, particularly miRNA, as candidates for liquid biopsy biomarkers. 


\section{Extracellular Vesicles (EVs)}

EVs are a heterogeneous group of membrane-bound particles released from all human cells [33]. They have become of particular interest to cancer biomarker researchers due to the ability of tumour cells to secrete large amounts of EVs that contain protected tumour-specific cargo [34-36]. EVs also have a role as functional mediators of cancer cell biology. They can act in a paracrine fashion locally within the tumour microenvironment, and in an endocrine manner at distal sites via the circulation [37-39]. Pathophysiological functions of EVs in cancer include promotion of tumour invasiveness and growth [40,41], stimulation of stromal accessory cells to tumour-supporting phenotypes [42], and preparation of pre-metastatic niches in distant organs [43].

EVs are divided into three main categories based on biogenesis: Exosomes $(\sim 40-100 \mathrm{~nm})$ are derived from multivesicular bodies within the cell's endosomal system; microvesicles (or ectosomes/microparticles; $100 \mathrm{~nm}-1 \mu \mathrm{m})$ are formed from outward budding of the plasma membrane [44-46]; and apoptotic bodies $(1-5 \mu \mathrm{m})$ arise from dying cells undergoing apoptosis [47-49]. In addition to these classes, some cancer-specific subtypes of EVs have been identified. Oncosomes (100-400 nm) are produced by non-transformed cells and their contents can produce oncogenic effects [50,51], whereas large oncosomes $(1-10 \mu \mathrm{m})$ arise from malignant cells and are more atypical in morphology [52-54]. There is still significant disparity in the classification and analysis of EV subtyping in the literature, as well as inconsistencies in the isolation of "specific" EV subtypes. For this reason, we use the collective term EVs when referring to studies in this review.

EVs contain a range of cargo that reflect the parent cell of origin, including RNA, DNA, protein, and lipids [37,55]. DNA ranging in size from 100 base pairs to 2.5 kilobases has been identified within EVs [56]. Protein contents of EVs are related to both the route of biogenesis and the parent cell of origin. Commonly reported sub-classes of EV proteins include tetraspanins (e.g., CD53, CD63, CD81, and CD82) and accessory proteins essential to forming multivesicular bodies (Alix and TSG101) $[44,47,57,58]$. Surface proteins that may be enriched in CRC-derived EVs include A33, EpCAM, and CD147 [20,59]. Transfer of EV cargo between cells and subsequent functional effects have been demonstrated in numerous studies, highlighting the potential of EVs as both biomarkers and functional mediators of disease [46].

One of the most extensively studied classes of EV cargo to date has been miRNA, which are single-stranded, non-coding RNA molecules of approximately 18-22 nucleotides [60]. miRNA have been implicated in a host of normal biochemical processes, including cell differentiation, proliferation, and apoptosis [60-63]. miRNA levels are significantly dysregulated in CRC tumour tissue compared to normal colonic mucosa, and are thought to play a variety of roles in tumour development and biology $[7,64,65]$. In addition, accumulating evidence supports the existence of unique miRNA profiles in body fluids that may function as both diagnostic and prognostic biomarkers for cancer [66-68]. Circulating miRNAs remain stable in serum or plasma under a host of unfavourable conditions, including extremes of temperature and repeated freeze-thaw cycles [31,32], making them a highly appealing class of blood-based biomarkers. The stability of miRNAs in the circulation is due to their association with carrier molecules that protect them from degradation by RNAses [32]. This includes proteins such as Argonaute-2 and lipoprotein complexes, in addition to the aforementioned EVs $[69,70]$.

\section{EV-miRNAs as Diagnostic Biomarkers in CRC}

There is some evidence that EV-specific miRNA may be of greater utility with regard to developing liquid biopsies in early stage CRC compared to total circulating miRNA levels. This is based on the concept that EV-miRNA profiles are more specific for tumour-derived signatures than total circulating miRNA due to the large volume of EVs released by tumour cells [6]. While sources of circulating EVs include platelets, red blood cells, and immune cells, in addition to tumour cells, CRC tumour cells release EVs in abundance in vitro [71,72]. Furthermore, EVs expressing specific surface markers can be isolated from the circulation to increase the specificity of tumour-derived EV biomarkers. One recent study has reported that the levels of CD147-expressing EVs are increased in the circulation of CRC patients versus controls as measured by flow cytometry [59]. Examples of other proposed enriched 
CRC-EV markers include EpCAM and A33 [20]. Interestingly, it also appears that cancer EVs contain higher levels of miRNA and can process pre-miRNA to mature miRNA [73]. This is a feature that is not present in EVs derived from normal cells, and may enhance the specificity of EV-miRNA as biomarkers of disease. Together, these data suggest that EV-miRNAs have significant potential as diagnostic biomarkers, due to being both robust in the circulation and storage in addition to their precision in reflecting the contents of their cell of origin.

\section{Candidate EV-miRNAs for Use as Diagnostic Biomarkers}

There have been numerous EV-miRNAs suggested as possible diagnostic markers in CRC. The most promising candidates that have been identified in one or more studies are outlined in Tables 1 and 2. Research has also focused on using panels of EV-miRNAs, whereby measurement of multiple EV-miRNAs might offer improved diagnostic accuracy when combined, compared to any lone EV-miRNA. Studies have focused mainly on EV-miRNA derived from serum, plasma, or in vitro CRC cell lines.

It should be noted that EV-miRNAs have also been posited as useful prognostic markers in CRC. A number of EV-miRNAs are associated with progression of CRC or poorer overall survival. Specific examples include: Decreased expression of miR-4772 being significantly associated with recurrence of CRC [74] miR-27a and miR-130a being associated with poorer 5-year survival [75] and EV miR-30 being associated with metastatic progression of CRC [74]. For the purposes of this review, we focus on the use of EV-miRNAs in the diagnostic setting.

Table 1. Extracellular vesicle (EV)-micro RNAs (miRNAs) in plasma and serum.

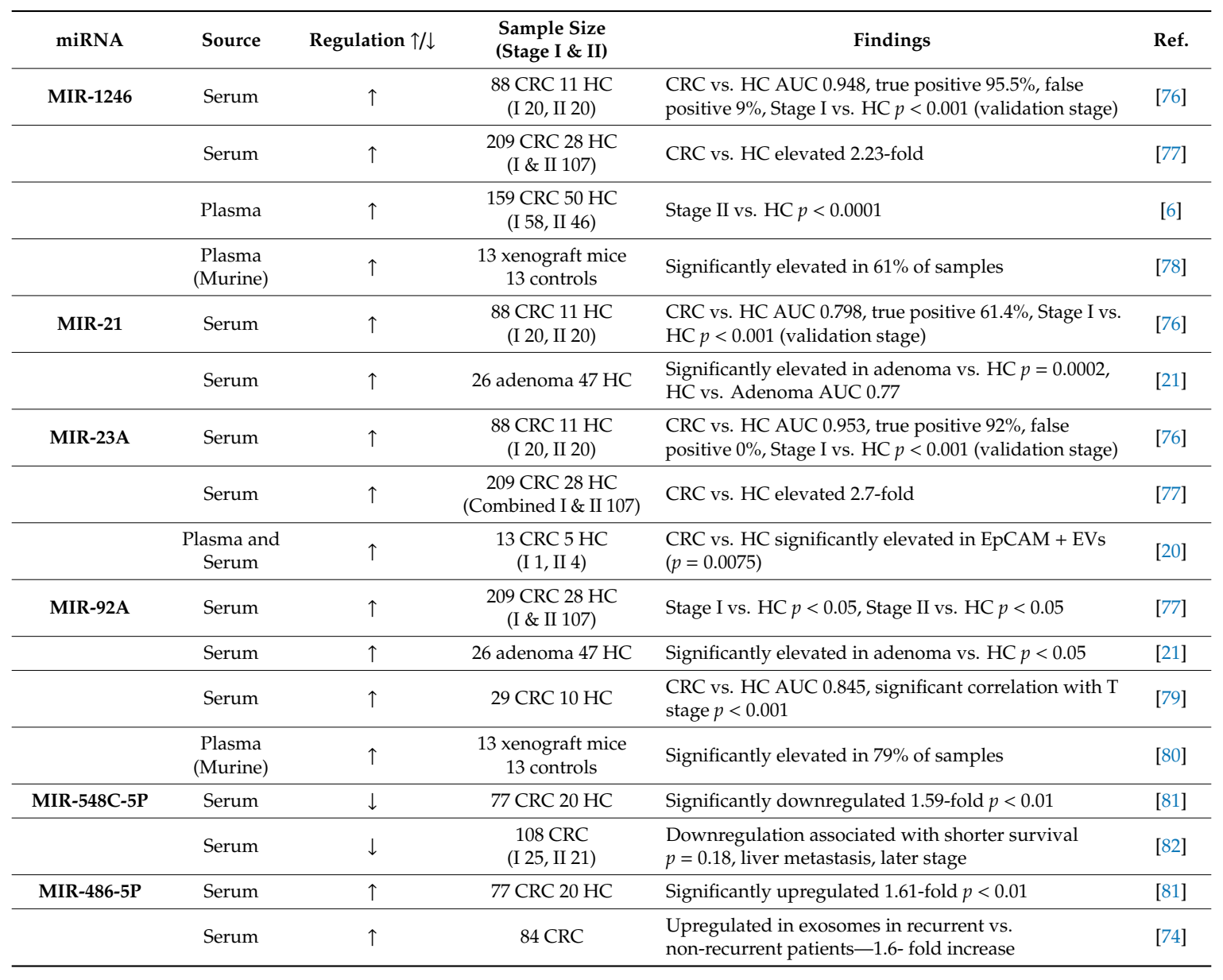


Table 1. Cont.

\begin{tabular}{cccccc}
\hline miRNA & Source & Regulation $\uparrow / \downarrow$ & $\begin{array}{c}\text { Sample Size } \\
\text { (Stage I \& II) }\end{array}$ & Findings \\
\hline MIR-17 & Serum & $\uparrow$ & 29 CRC 10 HC & $\begin{array}{c}\text { CRC vs. HC AUC 0.897, significant correlation with T } \\
\text { stage } p<0.001\end{array}$ \\
\hline [79] & [ & $\begin{array}{c}\text { 209 CRC 28 HC } \\
\text { (I \& II 107) }\end{array}$ & Stage I vs. HC $p<0.001$, Stage II vs. HC $p<0.001$ & [77] \\
\hline MIR-125A-3P & Plasma & $\uparrow$ & $\begin{array}{c}50 \text { CRC 50 HC } \\
\text { (I 3, II 47) }\end{array}$ & Stage I and II vs. HC $p=0.0035$, CRC vs. HC AUC 0.68 & [83] \\
\hline MIR-125A-5P & Plasma & $\downarrow$ & $\begin{array}{c}100 \text { CRC 50 HC } \\
\text { (I 25, II 25) }\end{array}$ & $\begin{array}{c}\text { AUC 0.62, 0.76, 0.74, 0.77 for stages I-IV vs. HC } \\
\text { respectively, overall AUC 0.75 }\end{array}$ \\
\hline
\end{tabular}

HC: Healthy control; I: Stage I; II: Stage II; $\uparrow:$ Upregulated; $\downarrow$ : Downregulated; AUC: Area under the curve.

Table 2. EV-miRNAs from in-vitro colorectal cancer (CRC) cell lines.

\begin{tabular}{|c|c|c|c|c|}
\hline miRNA & $\begin{array}{c}\text { Source } \\
\text { (CRC Cell Line) }\end{array}$ & Regulation $\uparrow / \downarrow$ & Findings & Ref. \\
\hline \multirow[t]{3}{*}{ miR-1246 } & LM1863 & $\uparrow$ & Elevated in $\mathrm{A} 33+$ and EpCAM + exosomes & [85] \\
\hline & HCT116 & $\uparrow$ & Highly expressed in EVs from HCT116 cell line & [86] \\
\hline & $\begin{array}{l}\text { DLD-1, WiDr, } \\
\text { SW480, COLO201 }\end{array}$ & $\uparrow$ & $\begin{array}{l}\text { Extracellular EV levels were significantly elevated } \\
\text { compared to intracellular levels } p<0.01\end{array}$ & [78] \\
\hline \multirow[t]{2}{*}{$\operatorname{miR}-21$} & $\begin{array}{l}\mathrm{CaCo} 2, \mathrm{SW} 480 \\
\text { HT29 }\end{array}$ & $\uparrow$ & Elevated in EVs in all cell lines & [87] \\
\hline & SW480, WiDr & $\uparrow$ & Elevated in EVs in SW480, WiDr cell lines & {$[88]$} \\
\hline miR-23a & LM1863 & $\uparrow$ & Elevated in $\mathrm{A} 33+$ and EpCAM + EVs & [85] \\
\hline \multirow[t]{4}{*}{ miR-200c } & LM1863 & $\uparrow$ & Elevated in A33+ and EpCAM + EVs & [85] \\
\hline & $\begin{array}{l}\mathrm{CaCo} 2, \mathrm{SW} 480 \\
\text { HT29 }\end{array}$ & $\uparrow$ & Elevated in EVs in all cell lines & [87] \\
\hline & SW480, SW620 & $\uparrow$ & $\begin{array}{l}\text { Present in EVs, increased in metastatic cell line } \\
\text { following treatment with decitabine }\end{array}$ & [89] \\
\hline & CCL227 & $\uparrow$ & $\begin{array}{l}\text { Upregulated in primary CRC, decreased level in EVs } \\
\text { associated with increased invasiveness }\end{array}$ & {$[90]$} \\
\hline miR-203a & LM1863 & $\uparrow$ & Elevated in A33+ and EpCAM + EVs & [85] \\
\hline \multirow[t]{2}{*}{$\operatorname{miR}-145$} & DLD-1 & $\uparrow$ & Upregulated in EVs compared to intracellular levels & [91] \\
\hline & DLD-1 & $\uparrow$ & Higher EV levels in 5-FU resistant cells & [92] \\
\hline $\operatorname{miR}-17$ & SW480, SW620 & $\uparrow$ & $\begin{array}{l}\text { Primary and metastatic cell line EVs both significantly } \\
\text { upregulated compared to normal mucosa } p<0.01\end{array}$ & [79] \\
\hline miR-19a & LM1863 & $\uparrow$ & Elevated in A33+ EVs & [85] \\
\hline \multirow[t]{2}{*}{$\operatorname{miR}-7641$} & LM1863 & $\uparrow$ & Elevated in $\mathrm{A} 33+$ and EpCAM+ EVs & [85] \\
\hline & SW480, SW620 & $\uparrow$ & $\begin{array}{l}\text { Significantly enriched (log2FC 6.1-11.5) in both SW480 } \\
\text { and SW620 EVs }\end{array}$ & [6] \\
\hline
\end{tabular}

HC: Healthy control; $\uparrow:$ Upregulated; $\downarrow$ : Downregulated; log2FC: $\log 2$ fold change.

\section{Diagnostic EV-miRNAs in Plasma and Serum}

EV-miRNAs from plasma and serum that have been found to be dysregulated in CRC are listed in Table 1 . There is significant variability with regard to the number of early stage patients included, which has the most relevance to applications as diagnostic or screening biomarkers. Ogata-Kawata and colleagues evaluated a cohort of 88 CRC patients, of which 20 each had stage I and stage II disease. They assessed the ability of various serum EV-miRNAs in differentiating these CRC patients from 11 controls. Their findings demonstrated that miR-23a, miR-1246, and miR-21 were able to differentiate CRC patients (all stages) from controls with an area under the curve (AUC) of 0.953, 0.948, and 0.798, respectively. A further validation cohort with a total of 7 stage I and 6 stage II patients vs. 8 controls demonstrated a significant difference in these EV-miRNAs between controls and stage I and II CRC combined $(p<0.001$ for miR-1246; $p<0.0001$ for miR-23a and miR-21) [76]. 
Serum EV miR-21 has similarly been found to be elevated in colonic adenoma, and can differentiate adenoma from controls with a sensitivity and specificity of $73.1 \%$ and $68.1 \%$, respectively, corresponding to an AUC of 0.77 [21]. These data suggest that miR-21 could be elevated in serum EVs from early in the adenoma-carcinoma sequence and remains elevated in late stage disease, demonstrating obvious potential as a diagnostic biomarker [93]. Unfortunately, serum EV miR-21 does not appear to be exclusively dysregulated in CRC. It has also been observed to be elevated in hepatocellular, oesophageal, and breast cancers, as well as non-malignant conditions such as acute kidney injury [94-97]. This would be a barrier to its adoption as a population-screening tool as it may lack specificity for CRC. However, markers such as this may still have a role in population-based screening, in conjunction with existing methods. If employed following a positive FIT, miR-21 elevation might indicate a higher probability that CRC is present. It could then be used in combination with FIT to shorten time to wait for definitive diagnosis for these higher risk patients.

Yan and colleagues, found upregulation of miR-486 and downregulation of miR-548c when comparing serum EV-miRNA from 77 CRC patients, of which 26 were stage I and II, compared to 20 healthy controls [81]. Liu et al. likewise found elevated miR-486 levels in the serum EVs of CRC patients of all stages [74]. Downregulation of serum EV miR-548c was also reported by Peng and colleagues in 108 CRC patients (including 25 stage I and 21 stage II patients) and was associated with shorter survival and liver metastases [82]. However, in this study, miR-548c was demonstrated to have a 1.59-fold decrease and miR-486 was shown to have a 1.61-fold increase. While these differences are significant, their relatively low absolute change may lead to substantial overlap in levels between CRC and healthy patients, thus limiting their ability to differentiate between the two groups.

Matsumara et al. found that miR-1246 and miR-23a were elevated 2.23- and 2.7-fold, respectively, when comparing serum EV-miRNA from a group of 209 CRC patients, of which 107 were stage I and II, against 28 controls. Their findings also demonstrated a significant elevation of miR-92a, both in stage I and stage II patients ( $p<0.05$ for both) [77]. Chen et al. also described increased EV miR-1246 in 46 stage II patients compared to 50 controls $(p<0.0001)$ [6]. Yamada et al. again demonstrated elevation of plasma EV-derived miR-1246 and miR-92a in 13 mice bearing colon cancer xenografts $[87,88]$. Similarly, serum EV miR-92a is significantly elevated in patients with colonic adenoma and CRC when compared to controls [21,79]. In summary, miR-92a appears to be consistently elevated in both adenoma and early stage CRC $[21,77,79]$.

\section{EV-miRNAs in CRC Cell Lines and Tumour Tissue}

To determine tumour-specific EV-miRNA markers, analysis was performed from EVs isolated from in vitro CRC cell line models (Table 2). There is some overlap between cell line-derived EV-miRNAs and the circulating EV-miRNAs in Table 1. Ji and colleagues used anti-EpCAM and anti-A33 antibodies to isolate EVs from CRC cell culture media [85]. They demonstrated elevation of miR-1246 and miR-23a in both A33- and EpCAM-positive EVs compared to the CRC cell lysate. These miRNAs are also elevated in serum-derived EVs of CRC patients [76]. Other studies have also found miR-1246 to be upregulated in EVs derived from a number of in vitro cell lines [78,86]. Additionally, Ji et al. found elevation of miR-19a and miR-203a in A33-positive EVs isolated from CRC cell line culture compared to CRC cell lysate. Both of these miRNAs have been similarly shown upregulated in serum EVs (see Table 1) [85].

miR-1246 has been observed to be both elevated and suppressed in CRC tumours compared to normal colonic tissue $[78,98]$. Scarpati and colleagues examined CRC tissue from 57 CRC patients, of which 24 were stage I and II, compared to normal stroma. Their results found miR-1246 to be upregulated relative to normal colonic tissue, with a 2.1-fold change $(p<0.0001)$ [98]. Yamada et al., conversely, demonstrated decreased expression of miR-1246 in tumour tissue compared to normal colonic tissue in 33 CRC patients, of which 13 were stage I and II [78]. Methodology differed in the processing of tissue samples between these studies. Scarpati and colleagues isolated tissue samples 
from formalin-fixed, paraffin-embedded (FFPE) slides, whereas Yamada et al. immediately froze the CRC tissue in liquid nitrogen $[78,98]$. This may be a possible reason for conflicting findings.

Yamada and colleagues also examined EVs isolated from CRC culture media from DLD-1, WiDr, SW480, and COLO201 cell lines [78]. Their findings demonstrated a significant enrichment in expression of miR-1246 within the EVs when compared to intracellular levels $(p<0.01)$ [78]. A further study also observed a similar pattern; miR-1246 was found to be elevated in CRC cell culture media EVs when isolated from the LM1863 cell line when compared to the cell lysate [85]. The findings of these studies suggest that miR-1246 may be packaged into EVs and subsequently released from CRC cells.

Similarly, miR-21 is upregulated in EVs isolated from CRC cell culture media, in addition to the circulation $[87,88]$. Upregulation of miR-200c from CRC cell line-derived EVs has also been found in at least four different studies; however, its presence in EVs in the peripheral circulation does not appear to have been established $[85,87,89,90]$. Although it has been demonstrated to be significantly upregulated in EVs isolated from mesenteric vein blood $(p=0.02)$ [99], it is possible that levels of miR-200c are altered by passing through the liver before joining the systemic circulation.

CRC cell culture models have also been used to examine the functional role of miRNAs. Whilst fully establishing the effect that miRNAs have on many biological processes is far from complete, there are links between some of the miRNAs outlined and oncogenic functions. This promotes the concept that using functional, rather than passive, biomarkers may be more useful when attempting to establish candidate molecules that can be adapted to a clinical setting. Functional biomarkers that have an active role in the disease process may be more likely to become dysregulated and change in tandem with progression of disease. Examples of miRNA biomarkers with oncogenic functions include miR-21, miR-1246, and miR-23a.

High expression of miR-21 in CRC cell culture has been associated with activation of the Wnt/ $\beta$-catenin pathway that may promote tumour development, proliferation, and progression [100,101]. In addition, it is implicated in promoting the epithelial-to-mesenchymal transition, a key step in the formation of metastasis [102]. miR-1246 may have a role in promoting tumour progression. Yamada et al. demonstrated that miR-1246 is transported in EVs, which affects Smad signaling and modulates the tumour environment to promote angiogenesis and tumour growth [78]. miR-23a, which forms a cluster with miR-27a and miR-24-2, appears to be elevated in stage I and II CRC tissue, with a subsequent increase in miR-27a in more advanced cancers. The authors suggest that miR-23a promotes the migration and invasion of CRC cells, whereas miR-27a primarily promotes tumour proliferation [103].

\section{Non-miRNA Non-Coding RNA}

In addition to miRNAs, there are other types of non-coding RNA that are dysregulated in CRC and are detectable in EVs [104-106]. To date, these have not been explored to the same extent as miRNAs. There have been several recent studies that have begun to investigate their role in CRC; however, the expression of these candidate biomarkers in EVs in CRC remains to be examined. Examples of these molecules include long non-coding RNA (lncRNA) and circular RNA (circRNA); both have been found to be differentially expressed in EVs from CRC cell lines and may have potential as diagnostic biomarkers in CRC $[107,108]$. Graham et al. examined the lncRNA CRNDE and found it to be upregulated in CRC tumour tissue $(n=161)$ and adenoma $(n=29)$ compared to normal colon tissue from control patients $(n=222)$ [109]. A subsequent validation cohort of 20 CRC, 21 adenoma, and 30 control patients demonstrated an ability to discriminate adenoma and normal tissue, with a sensitivity and specificity of $95 \%$ and $96 \%$, respectively, with an AUC of 0.938 . Their study also looked at CRNDE levels in total plasma from $15 \mathrm{CRC}$ and 15 control patients; this demonstrated a 5.5-fold increase in plasma from CRC patients and a subsequent AUC of 0.873 [109]. CCAT1, another IncRNA, has also been shown to be upregulated in CRC tumour tissue compared to matched normal mucosa, and adenoma compared to healthy controls [110]. Furthermore, a circRNA (circ_001988) has been shown to differentiate CRC tissue from normal mucosa in 31 CRC patients, of which 15 were stage I and II, with an AUC of 0.788 [111]. It also had a significant association with tumour differentiation and 
perineural invasion [111]. The role of CRNDE, CCAT1, and circ-001988 with respect to circulating EVs in CRC has not yet been examined.

Small nucleolar RNA (snoRNA) and PIWI-interacting RNA (piRNA) have also shown association with CRC. In a cohort of 188 CRC patients, high expression of SNORA42 in CRC tumours was associated with poorer overall survival, disease-free survival, and distant metastasis when compared to tumours with low expression; however, EVs were not assessed [112]. To date, one EV piRNA, piR-019825, has been examined. It was included with six miRNAs isolated from plasma EVs to form a panel that was effective in differentiating early stage CRC from healthy controls, discussed in Section 10 [84].

With regard to non-coding RNA in EVs, miRNAs have been the most extensively studied. It can be seen from the above research that there is also a significant amount of dysregulation in CRC with these other types of non-coding RNA. The current landscape for these novel molecules is rapidly developing. Similar types of non-coding RNA are known to be present in EVs in the circulation, and further research into their role as biomarkers in CRC with respect to EVs may be beneficial [104-106].

\section{0. miR Panels}

Combining a number of EV-miRNAs together in a panel is another option that is the focus of ongoing research. An obstacle in finding a single EV-miRNA that can function as a liquid biopsy marker is that most of the EV-miRNAs discussed have been implicated in multiple pathologies, both malignant and benign [113-115]. A further difficulty is that, by its nature, CRC tumorigenesis is not an organised and regulated process. There may be diversity of EV-miRNA profiles produced by CRC tumours. Due to this, a panel of EV-miRNAs have been employed in some studies to attempt to mitigate against this inherent heterogeneity.

Yuan et al. developed a six EV-miRNA panel that consisted of miR-1343, -125a, -708, -381, -543, and piR_019825 in 100 CRC patients ( 25 for each stage I-IV) and 50 controls. Their results demonstrated that both miR-125a and miR-1343 were significantly downregulated in the plasma EVs of all stages I-IV compared to controls (false discovery rate (FDR) $<0.05$ for stage I vs. control and FDR $<0.05$ for stage II vs. control for both miRNAs). Their six EV-miRNA panel was able to differentiate CRC from healthy controls with an AUC of $0.68,0.77,0.78$, and 0.81 for stages I-IV, respectively. This was superior to any lone EV-miRNA, the the best performing of which were miR-125a that had an AUC of 0.62 and 0.76 for stages I and II, respectively, and miR-1343 which had an AUC of 0.59 and 0.72 for stages I and II, respectively [84].

Similarly, Ogata-Kawata and colleagues studied seven EV-miRNAs (let-7a, miR-21, -23a, -223, $-150,-1229,-1246)$ which were all elevated in EVs from CRC patients' serum and from CRC cell lines [76]. This study group included 88 CRC patients, of which 20 each were stage I and stage II, as well as 11 healthy controls. Combined use of this panel did not show increased diagnostic power compared to miR-1246 or miR-23a alone, which had AUC values of 0.948 and 0.953 for all stages of CRC, respectively [76].

\section{Challenges in Using miRNAs as Diagnostic Biomarkers}

There are a number of challenges in developing miRNA liquid biopsies in CRC. Much research has focused on total circulating, rather than EV-specific miRNA levels. Advantages of this include that there is no need to isolate EVs from which to extract miRNAs. This has efficiency benefits with regard to sample processing, but with potentially lower specificity [116].

Certain methods of EV isolation may not be easily scalable to the higher throughput of a hospital laboratory. Ultracentrifugation (UC), including density gradient and differential UC, is a commonly used method of EV isolation [6,20,76,77,79]. It is limited by the number of wells in the ultracentrifuge machine, usually six, in addition to taking up to $18 \mathrm{~h}$ to process samples [6]. Other methods of EV isolation, such as size exclusion chromatography (SEC) columns may be more easily translated to a clinical setting. These techniques are relatively rapid (approximately $15 \mathrm{~min}$ processing) and the number of samples that can be processed is only limited by the number of columns available. It is 
also possible to automate the process of isolating the EVs as they pass through the column [117]. This has possible efficiency benefits over a method such as UC, with potential of ease of scalability and automation. Other methods of EV isolation include precipitation and filtration that were also in a number of studies [74,80-82,118]. Differences in EV isolation methods, including UC, precipitation, and SEC, have demonstrated significant variance in the properties of the isolated vesicles, the total miRNA yield, as well as the EV-specific miRNA levels when analysing the same samples [119,120].

Other technical considerations that may contribute to conflicting results include the use of "housekeepers", which are genes or miRNAs, which should not change in expression between controls and CRC. There was no consistency with the use of these housekeepers with multiple candidates chosen; examples include endogenous RNAs (e.g., RNU43), endogenous miRNAs (miR-16a, mir-451), and exogenous "spike in" controls (cel-miR-39-3p) [6,20,77]. This may introduce variance in the methods that might explain heterogeneity in the results. In addition, whether serum or plasma produce a higher miRNA yield is an area in which there is contradictory evidence. Contamination of a sample due to haemolysis, platelets, or other impurities may also contribute [121-123]. Wang et al. found that serum produced higher miRNA yields, whereas, conversely, McDonald and colleagues reported that plasma levels were higher [121,124]. Selection of control patients in this population can also be a contributing factor to inter-study variability. It is possible that "healthy controls" may have underlying adenoma or CRC, which can only be revealed via colonoscopy; up to 50\% of patients under investigation for CRC by colonoscopy will have polyps [125]. The majority of studies did not state that all of their controls had a normal colonoscopy prior to recruitment.

There is a need to standardise methodology and develop technologies that make the isolation and detection of EVs feasible and scalable to the higher throughput of a hospital laboratory. Global adoption of the Minimal Information for Studies of Extracellular Vesicles (MISEV) 2018 guidelines across EV research may be a useful starting point to address some of these methodological issues [126].

It is necessary to evaluate how EV-miRNA diagnostic biomarkers can be integrated into a modern healthcare system. Ideally, a blood-based biomarker would outperform current faecal-based assays on all parameters for screening. However, isolating a single miRNA or miRNA panel that is both sensitive and specific to CRC may prove challenging. Using biomarkers in conjunction with current screening methods may provide an avenue for their initial adoption to clinical practice. Adopting a blood-based test following negative FIT in the context of ongoing symptoms suggestive of CRC is one option. Another possibility may be using blood-based markers to triage time to wait for colonoscopy. If there is a positive FIT in conjunction with a blood-based biomarker suggestive of CRC, investigations could be expedited to aid in earlier diagnosis and treatment.

\section{Conclusions}

EV-associated miRNAs appear to have great potential as biomarkers in CRC. Currently there are a number of challenges; standardisation of methodology may help with identifying candidate miRNAs that offer the greatest potential as liquid biopsies. Some of the results for circulating EV-miRNAs, including miR-23a, miR-1246, and miR-92a, are encouraging. A widespread issue with the field of miRNAs appears to be isolating markers that are specific to a certain disease, such as CRC. Most of the miRNAs discussed are dysregulated in a wide number of pathologies. Due to this, the concept of an miRNA panel has the potential to mitigate against some of these issues of specificity. Identifying a blood-based biomarker for CRC screening which outperforms faecal-based testing would be likely to significantly increase uptake in CRC screening. This, currently, is in the region of $50 \%$ of the eligible population. The subsequent effects would likely include earlier diagnosis of CRC and, thus, improved outcomes for the millions of people who will be affected by this disease.

Author Contributions: Conceptualization, B.J.D., E.R.D. and K.M.D., Data Curation, B.J.D., E.R.D. and K.M.D.; Writing-Original Draft Preparation, B.J.D.; Writing-Review \& Editing, E.R.D. and K.M.D.; Funding Acquisition, B.J.D. and K.M.D. All authors have read and agreed to the published version of the manuscript. 
Funding: This work was supported by a research grant from Research for Life, Wellington Medical Research Foundation (reference 2019/304), Wellington, New Zealand.

Conflicts of Interest: The authors declare no conflict of interest.

\section{References}

1. Bray, F.; Ferlay, J.; Soerjomataram, I.; Siegel, R.L.; Torre, L.A.; Jemal, A. Global cancer statistics 2018: GLOBOCAN estimates of incidence and mortality worldwide for 36 cancers in 185 countries. CA Cancer J. Clin. 2018, 68, 394-424. [CrossRef] [PubMed]

2. Arnold, M.; Sierra, M.S.; Laversanne, M.; Soerjomataram, I.; Jemal, A.; Bray, F. Global patterns and trends in colorectal cancer incidence and mortality. Gut 2017, 66, 683-691. [CrossRef] [PubMed]

3. Siegel, R.L.; Miller, K.D.; Jemal, A. Cancer statistics, 2019. CA Cancer J. Clin. 2019, 69, 7-34. [CrossRef] [PubMed]

4. Chiu, H.M.; Lee, Y.C.; Tu, C.H.; Chen, C.C.; Tseng, P.H.; Liang, J.T.; Shun, C.T.; Lin, J.T.; Wu, M.S. Association between early stage colon neoplasms and false-negative results from the fecal immunochemical test. Clin. Gastroenterol. Hepatol. 2013, 11, 832-838.e2. [CrossRef]

5. Li, L.M.; Liu, H.; Liu, X.H.; Hu, H.B.; Liu, S.M. Clinical significance of exosomal miRNAs and proteins in three human cancers with high mortality in China. Oncol. Lett. 2019, 17, 11-22. [CrossRef]

6. Chen, M.; Xu, R.; Rai, A.; Suwakulsiri, W.; Izumikawa, K.; Ishikawa, H.; Greening, D.W.; Takahashi, N.; Simpson, R.J. Distinct shed microvesicle and exosome microRNA signatures reveal diagnostic markers for colorectal cancer. PLoS ONE 2019, 14, e0210003. [CrossRef]

7. Slattery, M.L.; Herrick, J.S.; Pellatt, D.F.; Stevens, J.R.; Mullany, L.E.; Wolff, E.; Hoffman, M.D.; Samowitz, W.S.; Wolff, R.K. MicroRNA profiles in colorectal carcinomas, adenomas and normal colonic mucosa: Variations in miRNA expression and disease progression. Carcinogenesis 2016, 37, 245-261. [CrossRef]

8. Somerville, J.; Lynch, P.; Rodgers, C.; Jacob, G.; McCrory, D. Bowel cancer screening-are the patients truly asymptomatic? Gut 2013, 62, A40. [CrossRef]

9. Kim, D.H.; Pickhardt, P.J.; Taylor, A.J.; Leung, W.K.; Winter, T.C.; Hinshaw, J.L.; Gopal, D.V.; Reichelderfer, M.; Hsu, R.H.; Pfau, P.R. CT colonography versus colonoscopy for the detection of advanced neoplasia. N. Engl. J. Med. 2007, 357, 1403-1412. [CrossRef]

10. Vleugels, J.L.A.; van Lanschot, M.C.J.; Dekker, E. Colorectal cancer screening by colonoscopy: Putting it into perspective. Dig. Endosc. 2016, 28, 250-259. [CrossRef]

11. Tinmouth, J.; Lansdorp-Vogelaar, I.; Allison, J.E. Faecal immunochemical tests versus guaiac faecal occult blood tests: What clinicians and colorectal cancer screening programme organisers need to know. Gut 2015, 64, 1327-1337. [CrossRef] [PubMed]

12. Hirai, H.W.; Tsoi, K.K.; Chan, J.Y.; Wong, S.H.; Ching, J.Y.; Wong, M.C.; Wu, J.C.; Chan, F.K.; Sung, J.J.; Ng, S.C. Systematic review with meta-analysis: Faecal occult blood tests show lower colorectal cancer detection rates in the proximal colon in colonoscopy-verified diagnostic studies. Aliment. Pharmacol. Ther. 2016, 43, 755-764. [CrossRef] [PubMed]

13. Mousavinezhad, M.; Majdzadeh, R.; Akbari Sari, A.; Delavari, A.; Mohtasham, F. The effectiveness of FOBT vs. FIT: A meta-analysis on colorectal cancer screening test. Med. J. Islam. Repub. Iran. 2016, 30, 366. [PubMed]

14. Song, L.L.; Li, Y.M. Current noninvasive tests for colorectal cancer screening: An overview of colorectal cancer screening tests. World J. Gastrointest. Oncol. 2016, 8, 793-800. [CrossRef]

15. Lee, J.K.; Liles, E.G.; Bent, S.; Levin, T.R.; Corley, D.A. Accuracy of fecal immunochemical tests for colorectal cancer: Systematic review and meta-analysis. Ann. Intern. Med. 2014, 160, 171. [CrossRef]

16. Ellis, L.; Abrahao, R.; McKinley, M.; Yang, J.; Somsouk, M.; Marchand, L.L.; Cheng, I.; Gomez, S.L.; Shariff-Marco, S. Colorectal Cancer Incidence Trends by Age, Stage, and Racial/Ethnic Group in California, 1990-2014. Cancer Epidemiol. Biomark. Prev. 2018, 27, 1011-1018. [CrossRef]

17. Meere, D.; Connell, E.; Harvey, J. National Bowel Cancer Screening Program: Monitoring Report 2013-14; Australian Institute of Health and Welfare: Canberra, Australia, 2015.

18. Koo, S.; Neilson, L.J.; Von Wagner, C.; Rees, C.J. The NHS Bowel Cancer Screening Program: Current perspectives on strategies for improvement. Risk Manag. Healthc. Policy 2017, 10, 177-187. [CrossRef]

19. Osborne, J.M.; Wilson, C.; Moore, V.; Gregory, T.; Flight, I.; Young, G.P. Sample preference for colorectal cancer screening tests: Blood or stool? Open J. Prev. Med. 2012, 2, 326-331. [CrossRef] 
20. Ostenfeld, M.S.; Jensen, S.G.; Jeppesen, D.K.; Christensen, L.L.; Thorsen, S.B.; Stenvang, J.; Hvam, M.L.; Thomsen, A.; Mouritzen, P.; Rasmussen, M.H.; et al. miRNA profiling of circulating EpCAM(+) extracellular vesicles: Promising biomarkers of colorectal cancer. J. Extracell. Vesicles 2016, 5, 31488. [CrossRef]

21. Uratani, R.; Toiyama, Y.; Kitajima, T.; Kawamura, M.; Hiro, J.; Kobayashi, M.; Tanaka, K.; Inoue, Y.; Mohri, Y.; Mori, T.; et al. Diagnostic Potential of Cell-Free and Exosomal MicroRNAs in the Identification of Patients with High-Risk Colorectal Adenomas. PLoS ONE 2016, 11, e0160722. [CrossRef]

22. Duffy, M.J. Carcinoembryonic antigen as a marker for colorectal cancer: Is it clinically useful? Clin. Chem. 2001, 47, 624-630. [PubMed]

23. Gerlach, J.Q.; Kruger, A.; Gallogly, S.; Hanley, S.A.; Hogan, M.C.; Ward, C.J.; Joshi, L.; Griffin, M.D. Surface glycosylation profiles of urine extracellular vesicles. PLoS ONE 2013, 8, e74801. [CrossRef] [PubMed]

24. Fleischhacker, M.; Schmidt, B. Circulating nucleic acids (CNAs) and cancer-A survey. Biochim. Biophys. Acta 2007, 1775, 181-232. [CrossRef] [PubMed]

25. Flamini, E.; Mercatali, L.; Nanni, O.; Calistri, D.; Nunziatini, R.; Zoli, W.; Rosetti, P.; Gardini, N.; Lattuneddu, A.; Verdecchia, G.M.; et al. Free DNA and carcinoembryonic antigen serum levels: An important combination for diagnosis of colorectal cancer. Clin. Cancer Res. 2006, 12, 6985-6988. [CrossRef] [PubMed]

26. Boni, L.; Cassinotti, E.; Canziani, M.; Dionigi, G.; Rovera, F.; Dionigi, R. Free circulating DNA as possible tumour marker in colorectal cancer. Surg. Oncol. 2007, 16, S29-S31. [CrossRef] [PubMed]

27. Spindler, K.L.; Pallisgaard, N.; Andersen, R.F.; Brandslund, I.; Jakobsen, A. Circulating free DNA as biomarker and source for mutation detection in metastatic colorectal cancer. PLoS ONE 2015, 10, e0108247. [CrossRef] [PubMed]

28. DeVos, T.; Tetzner, R.; Model, F.; Weiss, G.; Schuster, M.; Distler, J.; Steiger, K.V.; Grutzmann, R.; Pilarsky, C.; Habermann, J.K.; et al. Circulating methylated SEPT9 DNA in plasma is a biomarker for colorectal cancer. Clin. Chem. 2009, 55, 1337-1346. [CrossRef]

29. Grützmann, R.; Molnar, B.; Pilarsky, C.; Habermann, J.K.; Schlag, P.M.; Saeger, H.D.; Miehlke, S.; Stolz, T.; Model, F.; Roblick, U.J.; et al. Sensitive detection of colorectal cancer in peripheral blood by septin 9 DNA methylation assay. PLoS ONE 2008, 3, e3759. [CrossRef]

30. Church, T.R.; Wandell, M.; Lofton-Day, C.; Mongin, S.J.; Burger, M.; Payne, S.R.; Castanos-Velez, E.; Blumenstein, B.A.; Rosch, T.; Osborn, N.; et al. Prospective evaluation of methylated SEPT9 in plasma for detection of asymptomatic colorectal cancer. Gut 2014, 63, 317-325. [CrossRef]

31. Wang, Q.; Huang, Z.; Ni, S.; Xiao, X.; Xu, Q.; Wang, L.; Huang, D.; Tan, C.; Sheng, W.; Du, X. Plasma miR-601 and miR-760 are novel biomarkers for the early detection of colorectal cancer. PLoS ONE 2012, 7, e44398. [CrossRef]

32. Mitchell, P.S.; Parkin, R.K.; Kroh, E.M.; Fritz, B.R.; Wyman, S.K.; Pogosova-Agadjanyan, E.L.; Peterson, A.; Noteboom, J.; O’Briant, K.C.; Allen, A.; et al. Circulating microRNAs as stable blood-based markers for cancer detection. Proc. Natl. Acad. Sci. USA 2008, 105, 10513-10518. [CrossRef] [PubMed]

33. Margolis, L.; Sadovsky, Y. The biology of extracellular vesicles: The known unknowns. PLoS Biol. 2019, 17, e3000363. [CrossRef] [PubMed]

34. Taylor, D.D.; Gercel-Taylor, C. MicroRNA signatures of tumor-derived exosomes as diagnostic biomarkers of ovarian cancer. Gynecol. Oncol. 2008, 110, 13-21. [CrossRef] [PubMed]

35. Szajnik, M.; Derbis, M.; Lach, M.; Patalas, P.; Michalak, M.; Drzewiecka, H.; Szpurek, D.; Nowakowski, A.; Spaczynski, M.; Baranowski, W.; et al. Exosomes in Plasma of Patients with Ovarian Carcinoma: Potential Biomarkers of Tumor Progression and Response to Therapy. Gynecol Obs. (Sunnyvale) 2013. [CrossRef]

36. Kalluri, R. The biology and function of exosomes in cancer. J. Clin. Invest. 2016, 126, 1208-1215. [CrossRef]

37. Valadi, H.; Ekstrom, K.; Bossios, A.; Sjostrand, M.; Lee, J.J.; Lotvall, J.O. Exosome-mediated transfer of mRNAs and microRNAs is a novel mechanism of genetic exchange between cells. Nat. Cell Biol. 2007, 9, 654-659. [CrossRef]

38. Lotvall, J.; Valadi, H. Cell to cell signalling via exosomes through esRNA. Cell Adhes. Migr. 2007, 1, 156-158. [CrossRef]

39. Tanaka, Y.; Kamohara, H.; Kinoshita, K.; Kurashige, J.; Ishimoto, T.; Iwatsuki, M.; Watanabe, M.; Baba, H. Clinical impact of serum exosomal microRNA-21 as a clinical biomarker in human esophageal squamous cell carcinoma. Cancer 2013, 119, 1159-1167. [CrossRef] 
40. Lucchetti, D.; Calapa, F.; Palmieri, V.; Fanali, C.; Carbone, F.; Papa, A.; De Maria, R.; De Spirito, M.; Sgambato, A. Differentiation Affects the Release of Exosomes from Colon Cancer Cells and Their Ability to Modulate the Behavior of Recipient Cells. Am. J. Pathol. 2017, 187, 1633-1647. [CrossRef]

41. Hanahan, D.; Weinberg, R.A. Hallmarks of cancer: The next generation. Cell 2011, 144, 646-674. [CrossRef]

42. Rai, A.; Greening, D.W.; Chen, M.; Xu, R.; Ji, H.; Simpson, R.J. Exosomes Derived from Human Primary and Metastatic Colorectal Cancer Cells Contribute to Functional Heterogeneity of Activated Fibroblasts by Reprogramming Their Proteome. Proteomics 2019, 19, e1800148. [CrossRef] [PubMed]

43. Sceneay, J.; Smyth, M.J.; Moller, A. The pre-metastatic niche: Finding common ground. Cancer Metastasis Rev. 2013, 32, 449-464. [CrossRef] [PubMed]

44. Heijnen, H.F.; Schiel, A.E.; Fijnheer, R.; Geuze, H.J.; Sixma, J.J. Activated platelets release two types of membrane vesicles: Microvesicles by surface shedding and exosomes derived from exocytosis of multivesicular bodies and alpha-granules. Blood 1999, 94, 3791-3799. [CrossRef] [PubMed]

45. Gasser, O.; Hess, C.; Miot, S.; Deon, C.; Sanchez, J.C.; Schifferli, J.A. Characterisation and properties of ectosomes released by human polymorphonuclear neutrophils. Exp. Cell Res. 2003, 285, 243-257. [CrossRef]

46. Thery, C.; Ostrowski, M.; Segura, E. Membrane vesicles as conveyors of immune responses. Nat. Rev. Immunol. 2009, 9, 581-593. [CrossRef]

47. Thery, C.; Boussac, M.; Veron, P.; Ricciardi-Castagnoli, P.; Raposo, G.; Garin, J.; Amigorena, S. Proteomic analysis of dendritic cell-derived exosomes: A secreted subcellular compartment distinct from apoptotic vesicles. J. Immunol. 2001, 166, 7309-7318. [CrossRef]

48. Andaloussi, S.E.L.; Mager, I.; Breakefield, X.O.; Wood, M.J. Extracellular vesicles: Biology and emerging therapeutic opportunities. Nat. Rev. Drug. Discov. 2013, 12, 347-357.

49. Zaborowski, M.P.; Balaj, L.; Breakefield, X.O.; Lai, C.P. Extracellular Vesicles: Composition, Biological Relevance, and Methods of Study. Bioscience 2015, 65, 783-797. [CrossRef]

50. Al-Nedawi, K.; Meehan, B.; Micallef, J.; Lhotak, V.; May, L.; Guha, A.; Rak, J. Intercellular transfer of the oncogenic receptor EGFRvIII by microvesicles derived from tumour cells. Nat. Cell Biol. 2008, 10, 619-624. [CrossRef]

51. Skog, J.; Wurdinger, T.; van Rijn, S.; Meijer, D.H.; Gainche, L.; Sena-Esteves, M.; Curry, W.T., Jr.; Carter, B.S.; Krichevsky, A.M.; Breakefield, X.O. Glioblastoma microvesicles transport RNA and proteins that promote tumour growth and provide diagnostic biomarkers. Nat. Cell Biol. 2008, 10, 1470-1476. [CrossRef]

52. Di Vizio, D.; Kim, J.; Hager, M.H.; Morello, M.; Yang, W.; Lafargue, C.J.; True, L.D.; Rubin, M.A.; Adam, R.M.; Beroukhim, R.; et al. Oncosome formation in prostate cancer: Association with a region of frequent chromosomal deletion in metastatic disease. Cancer Res. 2009, 69, 5601-5609. [CrossRef] [PubMed]

53. Di Vizio, D.; Morello, M.; Dudley, A.C.; Schow, P.W.; Adam, R.M.; Morley, S.; Mulholland, D.; Rotinen, M.; Hager, M.H.; Insabato, L.; et al. Large oncosomes in human prostate cancer tissues and in the circulation of mice with metastatic disease. Am. J. Pathol. 2012, 181, 1573-1584. [CrossRef] [PubMed]

54. Minciacchi, V.R.; Freeman, M.R.; Di Vizio, D. Extracellular vesicles in cancer: Exosomes, microvesicles and the emerging role of large oncosomes. Semin. Cell Dev. Biol. 2015, 40, 41-51. [CrossRef] [PubMed]

55. Simpson, R.J.; Lim, J.W.; Moritz, R.L.; Mathivanan, S. Exosomes: Proteomic insights and diagnostic potential. Expert Rev. Proteom. 2009, 6, 267-283. [CrossRef]

56. Thakur, B.K.; Zhang, H.; Becker, A.; Matei, I.; Huang, Y.; Costa-Silva, B.; Zheng, Y.; Hoshino, A.; Brazier, H.; Xiang, J.; et al. Double-stranded DNA in exosomes: A novel biomarker in cancer detection. Cell Res. 2014, 24, 766-769. [CrossRef]

57. Tauro, B.J.; Greening, D.W.; Mathias, R.A.; Mathivanan, S.; Ji, H.; Simpson, R.J. Two distinct populations of exosomes are released from LIM1863 colon carcinoma cell-derived organoids. Mol. Cell Proteomics 2013, 12, 587-598. [CrossRef]

58. Morita, E.; Sandrin, V.; Chung, H.Y.; Morham, S.G.; Gygi, S.P.; Rodesch, C.K.; Sundquist, W.I. Human ESCRT and ALIX proteins interact with proteins of the midbody and function in cytokinesis. EMBO J. 2007, 26, 4215-4227. [CrossRef]

59. Tian, Y.; Ma, L.; Gong, M.; Su, G.; Zhu, S.; Zhang, W.; Wang, S.; Li, Z.; Chen, C.; Li, L.; et al. Protein Profiling and Sizing of Extracellular Vesicles from Colorectal Cancer Patients via Flow Cytometry. ACS Nano 2018, 12, 671-680. [CrossRef]

60. Gopalakrishnan, C.; Kamaraj, B.; Purohit, R. Mutations in microRNA binding sites of CEP genes involved in cancer. Cell Biochem. Biophys. 2014, 70, 1933-1942. [CrossRef] 
61. Bhaumik, P.; Gopalakrishnan, C.; Kamaraj, B.; Purohit, R. Single nucleotide polymorphisms in microRNA binding sites: Implications in colorectal cancer. Sci. World J. 2014, 2014, 547154. [CrossRef]

62. Kamaraj, B.; Gopalakrishnan, C.; Purohit, R. In silico analysis of miRNA-mediated gene regulation in OCA and OA genes. Cell Biochem. Biophys. 2014, 70, 1923-1932. [CrossRef] [PubMed]

63. Kumar, A.; Purohit, R. Use of long term molecular dynamics simulation in predicting cancer associated SNPs. PLoS Comput. Biol. 2014, 10, e1003318. [CrossRef] [PubMed]

64. Meltzer, P.S. Cancer genomics: Small RNAs with big impacts. Nature 2005, 435, 745-746. [CrossRef] [PubMed]

65. Calin, G.A.; Croce, C.M. MicroRNA signatures in human cancers. Nat. Rev. Cancer 2006, 6, 857-866. [CrossRef]

66. Toiyama, Y.; Goel, A. The Diagnostic, Prognostic, and Predictive Potential of MicroRNA Biomarkers in Colorectal Cancer. Curr. Color. Cancer Rep. 2012, 8, 22-31. [CrossRef]

67. Nugent, M.; Miller, N.; Kerin, M.J. MicroRNAs in colorectal cancer: Function, dysregulation and potential as novel biomarkers. Eur. J. Surg. Oncol. 2011, 37, 649-654. [CrossRef]

68. Chen, X.; Ba, Y.; Ma, L.; Cai, X.; Yin, Y.; Wang, K.; Guo, J.; Zhang, Y.; Chen, J.; Guo, X.; et al. Characterization of microRNAs in serum: A novel class of biomarkers for diagnosis of cancer and other diseases. Cell Res. 2008, 18, 997-1006. [CrossRef]

69. El-Hefnawy, T.; Raja, S.; Kelly, L.; Bigbee, W.L.; Kirkwood, J.M.; Luketich, J.D.; Godfrey, T.E. Characterization of amplifiable, circulating RNA in plasma and its potential as a tool for cancer diagnostics. Clin. Chem. 2004, 50, 564-573. [CrossRef]

70. Arroyo, J.D.; Chevillet, J.R.; Kroh, E.M.; Ruf, I.K.; Pritchard, C.C.; Gibson, D.F.; Mitchell, P.S.; Bennett, C.F.; Pogosova-Agadjanyan, E.L.; Stirewalt, D.L.; et al. Argonaute2 complexes carry a population of circulating microRNAs independent of vesicles in human plasma. Proc. Natl. Acad. Sci. USA 2011, 108, 5003-5008. [CrossRef]

71. Manning, S.; Danielson, K.M. The immunomodulatory role of tumor-derived extracellular vesicles in colorectal cancer. Immunol. Cell Biol. 2018, 96, 733-741. [CrossRef]

72. Popena, I.; Abols, A.; Saulite, L.; Pleiko, K.; Zandberga, E.; Jekabsons, K.; Endzelins, E.; Llorente, A.; Line, A.; Riekstina, U. Effect of colorectal cancer-derived extracellular vesicles on the immunophenotype and cytokine secretion profile of monocytes and macrophages. Cell Commun. Signal. 2018, 16, 17. [CrossRef] [PubMed]

73. Melo, S.A.; Sugimoto, H.; O'Connell, J.T.; Kato, N.; Villanueva, A.; Vidal, A.; Qiu, L.; Vitkin, E.; Perelman, L.T.; Melo, C.A.; et al. Cancer exosomes perform cell-independent microRNA biogenesis and promote tumorigenesis. Cancer Cell 2014, 26, 707-721. [CrossRef] [PubMed]

74. Liu, C.; Eng, C.; Shen, J.; Lu, Y.; Takata, Y.; Mehdizadeh, A.; Chang, G.J.; Rodriguez-Bigas, M.A.; Li, Y.; Chang, P.; et al. Serum exosomal miR-4772-3p is a predictor of tumor recurrence in stage II and III colon cancer. Oncotarget 2016, 7, 76250-76260. [CrossRef] [PubMed]

75. Bjornetro, T.; Redalen, K.R.; Meltzer, S.; Thusyanthan, N.S.; Samiappan, R.; Jegerschold, C.; Handeland, K.R.; Ree, A.H. An experimental strategy unveiling exosomal microRNAs 486-5p, 181a-5p and 30d-5p from hypoxic tumour cells as circulating indicators of high-risk rectal cancer. J. Extracell Vesicles 2019, 8, 1567219. [CrossRef] [PubMed]

76. Ogata-Kawata, H.; Izumiya, M.; Kurioka, D.; Honma, Y.; Yamada, Y.; Furuta, K.; Gunji, T.; Ohta, H.; Okamoto, H.; Sonoda, H.; et al. Circulating exosomal microRNAs as biomarkers of colon cancer. PLoS ONE 2014, 9, e92921. [CrossRef]

77. Matsumura, T.; Sugimachi, K.; Iinuma, H.; Takahashi, Y.; Kurashige, J.; Sawada, G.; Ueda, M.; Uchi, R.; Ueo, H.; Takano, Y.; et al. Exosomal microRNA in serum is a novel biomarker of recurrence in human colorectal cancer. Br. J. Cancer 2015, 113, 275-281. [CrossRef]

78. Yamada, N.; Tsujimura, N.; Kumazaki, M.; Shinohara, H.; Taniguchi, K.; Nakagawa, Y.; Naoe, T.; Akao, Y. Colorectal cancer cell-derived microvesicles containing microRNA-1246 promote angiogenesis by activating Smad 1/5/8 signaling elicited by PML down-regulation in endothelial cells. Biochim. Biophys. Acta 2014, 1839, 1256-1272. [CrossRef]

79. Fu, F.; Jiang, W.; Zhou, L.; Chen, Z. Circulating Exosomal miR-17-5p and miR-92a-3p Predict Pathologic Stage and Grade of Colorectal Cancer. Transl. Oncol. 2018, 11, 221-232. [CrossRef]

80. Yamada, N.; Nakagawa, Y.; Tsujimura, N.; Kumazaki, M.; Noguchi, S.; Mori, T.; Hirata, I.; Maruo, K.; Akao, Y. Role of Intracellular and Extracellular MicroRNA-92a in Colorectal Cancer. Transl. Oncol. 2013, 6, 482-492. [CrossRef] 
81. Yan, S.; Han, B.; Gao, S.; Wang, X.; Wang, Z.; Wang, F.; Zhang, J.; Xu, D.; Sun, B. Exosome-encapsulated microRNAs as circulating biomarkers for colorectal cancer. Oncotarget 2017, 8, 60149-60158. [CrossRef]

82. Peng, Z.Y.; Gu, R.H.; Yan, B. Downregulation of exosome-encapsulated miR-548c-5p is associated with poor prognosis in colorectal cancer. J. Cell Biochem 2019, 120, 1457-1463. [CrossRef]

83. Wang, J.; Yan, F.; Zhao, Q.; Zhan, F.; Wang, R.; Wang, L.; Zhang, Y.; Huang, X. Circulating exosomal miR-125a-3p as a novel biomarker for early-stage colon cancer. Sci. Rep. 2017, 7, 4150. [CrossRef]

84. Yuan, T.; Huang, X.; Woodcock, M.; Du, M.; Dittmar, R.; Wang, Y.; Tsai, S.; Kohli, M.; Boardman, L.; Patel, T.; et al. Plasma extracellular RNA profiles in healthy and cancer patients. Sci. Rep. 2016, 6, 19413. [CrossRef]

85. Ji, H.; Chen, M.; Greening, D.W.; He, W.; Rai, A.; Zhang, W.; Simpson, R.J. Deep sequencing of RNA from three different extracellular vesicle (EV) subtypes released from the human LIM1863 colon cancer cell line uncovers distinct miRNA-enrichment signatures. PLoS ONE 2014, 9, e110314. [CrossRef]

86. Clancy, C.; Khan, S.; Glynn, C.L.; Holian, E.; Dockery, P.; Lalor, P.; Brown, J.A.; Joyce, M.R.; Kerin, M.J.; Dwyer, R.M. Screening of exosomal microRNAs from colorectal cancer cells. Cancer Biomark. 2016, 17, 427-435. [CrossRef]

87. Moshammer, M.I.; Kalipciyan, M.; Bartsch, R.; Steger, G.G.; Sedivy, R.; Mader, R.M. Exosomal microRNA transfer varies with specific microRNAs functional in colorectal cancer and cellular differentiation. Int. J. Clin. Pharmacol. Ther. 2014, 52, 87-88. [CrossRef]

88. Chiba, M.; Kimura, M.; Asari, S. Exosomes secreted from human colorectal cancer cell lines contain mRNAs, microRNAs and natural antisense RNAs, that can transfer into the human hepatoma HepG2 and lung cancer A549 cell lines. Oncol. Rep. 2012, 28, 1551-1558. [CrossRef]

89. Tanaka, S.; Hosokawa, M.; Ueda, K.; Iwakawa, S. Effects of Decitabine on Invasion and Exosomal Expression of miR-200c and miR-141 in Oxaliplatin-Resistant Colorectal Cancer Cells. Biol. Pharm. Bull. 2015, 38, 1272-1279. [CrossRef]

90. Holzner, S.; Senfter, D.; Stadler, S.; Staribacher, A.; Nguyen, C.H.; Gaggl, A.; Geleff, S.; Huttary, N.; Krieger, S.; Jager, W.; et al. Colorectal cancer cell-derived microRNA200 modulates the resistance of adjacent blood endothelial barriers in vitro. Oncol. Rep. 2016, 36, 3065-3071. [CrossRef]

91. Shinohara, H.; Kuranaga, Y.; Kumazaki, M.; Sugito, N.; Yoshikawa, Y.; Takai, T.; Taniguchi, K.; Ito, Y.; Akao, Y. Regulated Polarization of Tumor-Associated Macrophages by miR-145 via Colorectal Cancer-Derived Extracellular Vesicles. J. Immunol. 2017, 199, 1505-1515. [CrossRef]

92. Akao, Y.; Khoo, F.; Kumazaki, M.; Shinohara, H.; Miki, K.; Yamada, N. Extracellular disposal of tumor-suppressor miRs-145 and -34a via microvesicles and 5-FU resistance of human colon cancer cells. Int. J. Mol. Sci. 2014, 15, 1392-1401. [CrossRef]

93. Armaghany, T.; Wilson, J.D.; Chu, Q.; Mills, G. Genetic alterations in colorectal cancer. Gastrointest. Cancer Res. 2012, 5, 19-27.

94. Suehiro, T.; Miyaaki, H.; Kanda, Y.; Shibata, H.; Honda, T.; Ozawa, E.; Miuma, S.; Taura, N.; Nakao, K. Serum exosomal microRNA-122 and microRNA-21 as predictive biomarkers in transarterial chemoembolization-treated hepatocellular carcinoma patients. Oncol. Lett. 2018, 16, 3267-3273. [CrossRef]

95. Yang, Y.C.; Liu, G.J.; Yuan, D.F.; Li, C.Q.; Xue, M.; Chen, L.J. Influence of exosome-derived miR-21on chemotherapy resistance of esophageal cancer. Eur. Rev. Med. Pharmacol. Sci. 2019, 23, 1513-1519.

96. Abdulhussain, M.M.; Hasan, N.A.; Hussain, A.G. Interrelation of the Circulating and Tissue MicroRNA-21 with Tissue PDCD4 Expression and the Invasiveness of Iraqi Female Breast Tumors. Indian J. Clin. Biochem. 2019, 34, 26-38. [CrossRef]

97. Pan, T.; Jia, P.; Chen, N.; Fang, Y.; Liang, Y.; Guo, M.; Ding, X. Delayed Remote Ischemic Preconditioning ConfersRenoprotection against Septic Acute Kidney Injury via Exosomal miR-21. Theranostics 2019, 9, 405-423. [CrossRef]

98. Della Vittoria Scarpati, G.; Calura, E.; Di Marino, M.; Romualdi, C.; Beltrame, L.; Malapelle, U.; Troncone, G.; De Stefano, A.; Pepe, S.; De Placido, S.; et al. Analysis of differential miRNA expression in primary tumor and stroma of colorectal cancer patients. Biomed Res. Int. 2014, 2014, 840921. [CrossRef]

99. Santasusagna, S.; Moreno, I.; Navarro, A.; Martinez Rodenas, F.; Hernandez, R.; Castellano, J.J.; Munoz, C.; Monzo, M. Prognostic Impact of miR-200 Family Members in Plasma and Exosomes from Tumor-Draining versus Peripheral Veins of Colon Cancer Patients. Oncology 2018, 95, 309-318. [CrossRef] 
100. Falzone, L.; Scola, L.; Zanghi, A.; Biondi, A.; Di Cataldo, A.; Libra, M.; Candido, S. Integrated analysis of colorectal cancer microRNA datasets: Identification of microRNAs associated with tumor development. Aging (Albany NY) 2018, 10, 1000-1014. [CrossRef]

101. Fu, J.; Tang, W.; Du, P.; Wang, G.; Chen, W.; Li, J.; Zhu, Y.; Gao, J.; Cui, L. Identifying microRNA-mRNA regulatory network in colorectal cancer by a combination of expression profile and bioinformatics analysis. BMC Syst. Biol. 2012, 6, 68. [CrossRef]

102. Wang, H.; Nie, L.; Wu, L.; Liu, Q.; Guo, X. NR2F2 inhibits Smad7 expression and promotes TGF-betadependent epithelial-mesenchymal transition of CRC via transactivation of miR-21. Biochem. Biophys. Res. Commun. 2017, 485, 181-188. [CrossRef]

103. Jahid, S.; Sun, J.; Edwards, R.A.; Dizon, D.; Panarelli, N.C.; Milsom, J.W.; Sikandar, S.S.; Gumus, Z.H.; Lipkin, S.M. miR-23a promotes the transition from indolent to invasive colorectal cancer. Cancer Discov. 2012, 2, 540-553. [CrossRef]

104. Lasda, E.; Parker, R. Circular RNAs Co-Precipitate with Extracellular Vesicles: A Possible Mechanism for circRNA Clearance. PLoS ONE 2016, 11, e0148407. [CrossRef]

105. Takahashi, K.; Yan, I.K.; Kogure, T.; Haga, H.; Patel, T. Extracellular vesicle-mediated transfer of long non-coding RNA ROR modulates chemosensitivity in human hepatocellular cancer. FEBS Open Bio 2014, 4, 458-467. [CrossRef]

106. Kaur, S.; Abu-Shahba, A.G.; Paananen, R.O.; Hongisto, H.; Hiidenmaa, H.; Skottman, H.; Seppanen-Kaijansinkko, R.; Mannerstrom, B. Small non-coding RNA landscape of extracellular vesicles from human stem cells. Sci. Rep. 2018, 8, 15503. [CrossRef]

107. Dou, Y.; Cha, D.J.; Franklin, J.L.; Higginbotham, J.N.; Jeppesen, D.K.; Weaver, A.M.; Prasad, N.; Levy, S.; Coffey, R.J.; Patton, J.G.; et al. Circular RNAs are down-regulated in KRAS mutant colon cancer cells and can be transferred to exosomes. Sci. Rep. 2016, 6, 37982. [CrossRef]

108. Hinger, S.A.; Cha, D.J.; Franklin, J.L.; Higginbotham, J.N.; Dou, Y.; Ping, J.; Shu, L.; Prasad, N.; Levy, S.; Zhang, B.; et al. Diverse Long RNAs Are Differentially Sorted into Extracellular Vesicles Secreted by Colorectal Cancer Cells. Cell Rep. 2018, 25, 715-725. [CrossRef]

109. Graham, L.D.; Pedersen, S.K.; Brown, G.S.; Ho, T.; Kassir, Z.; Moynihan, A.T.; Vizgoft, E.K.; Dunne, R.; Pimlott, L.; Young, G.P.; et al. Colorectal Neoplasia Differentially Expressed (CRNDE), a Novel Gene with Elevated Expression in Colorectal Adenomas and Adenocarcinomas. Genes Cancer 2011, 2, 829-840. [CrossRef]

110. Nissan, A.; Stojadinovic, A.; Mitrani-Rosenbaum, S.; Halle, D.; Grinbaum, R.; Roistacher, M.; Bochem, A.; Dayanc, B.E.; Ritter, G.; Gomceli, I.; et al. Colon cancer associated transcript-1: A novel RNA expressed in malignant and pre-malignant human tissues. Int. J. Cancer 2012, 130, 1598-1606. [CrossRef]

111. Wang, X.; Zhang, Y.; Huang, L.; Zhang, J.; Pan, F.; Li, B.; Yan, Y.; Jia, B.; Liu, H.; Li, S.; et al. Decreased expression of hsa_circ_001988 in colorectal cancer and its clinical significances. Int. J. Clin. Exp. Pathol. 2015, $8,16020-16025$.

112. Okugawa, Y.; Toiyama, Y.; Toden, S.; Mitoma, H.; Nagasaka, T.; Tanaka, K.; Inoue, Y.; Kusunoki, M.; Boland, C.R.; Goel, A. Clinical significance of SNORA42 as an oncogene and a prognostic biomarker in colorectal cancer. Gut 2017, 66, 107-117. [CrossRef] [PubMed]

113. Li, X.J.; Ren, Z.J.; Tang, J.H.; Yu, Q. Exosomal MicroRNA MiR-1246 Promotes Cell Proliferation, Invasion and Drug Resistance by Targeting CCNG2 in Breast Cancer. Cell Physiol. Biochem. 2017, 44, 1741-1748. [CrossRef] [PubMed]

114. Yuan, J.; Chen, H.; Ge, D.; Xu, Y.; Xu, H.; Yang, Y.; Gu, M.; Zhou, Y.; Zhu, J.; Ge, T.; et al. Mir-21 Promotes Cardiac Fibrosis After Myocardial Infarction Via Targeting Smad7. Cell Physiol. Biochem. 2017, 42, 2207-2219. [CrossRef] [PubMed]

115. Roufayel, R.; Kadry, S. Expression of miR-23a by apoptotic regulators in human cancer: A review. Cancer Biol. Ther. 2017, 18, 269-276. [CrossRef] [PubMed]

116. Endzelins, E.; Berger, A.; Melne, V.; Bajo-Santos, C.; Sobolevska, K.; Abols, A.; Rodriguez, M.; Santare, D.; Rudnickiha, A.; Lietuvietis, V.; et al. Detection of circulating miRNAs: Comparative analysis of extracellular vesicle-incorporated miRNAs and cell-free miRNAs in whole plasma of prostate cancer patients. BMC Cancer 2017, 17, 730. [CrossRef] 
117. Corso, G.; Mager, I.; Lee, Y.; Gorgens, A.; Bultema, J.; Giebel, B.; Wood, M.J.A.; Nordin, J.Z.; Andaloussi, S.E. Reproducible and scalable purification of extracellular vesicles using combined bind-elute and size exclusion chromatography. Sci. Rep. 2017, 7, 11561. [CrossRef]

118. Yamada, A.; Cox, M.A.; Gaffney, K.A.; Moreland, A.; Boland, C.R.; Goel, A. Technical factors involved in the measurement of circulating microRNA biomarkers for the detection of colorectal neoplasia. PLoS ONE 2014, 9, e112481. [CrossRef]

119. Buschmann, D.; Kirchner, B.; Hermann, S.; Marte, M.; Wurmser, C.; Brandes, F.; Kotschote, S.; Bonin, M.; Steinlein, O.K.; Pfaffl, M.W.; et al. Evaluation of serum extracellular vesicle isolation methods for profiling miRNAs by next-generation sequencing. J. Extracell. Vesicles 2018, 7, 1481321. [CrossRef]

120. Coumans, F.A.W.; Brisson, A.R.; Buzas, E.I.; Dignat-George, F.; Drees, E.E.E.; El-Andaloussi, S.; Emanueli, C.; Gasecka, A.; Hendrix, A.; Hill, A.F.; et al. Methodological Guidelines to Study Extracellular Vesicles. Circ. Res. 2017, 120, 1632-1648. [CrossRef]

121. McDonald, J.S.; Milosevic, D.; Reddi, H.V.; Grebe, S.K.; Algeciras-Schimnich, A. Analysis of circulating microRNA: Preanalytical and analytical challenges. Clin. Chem. 2011, 57, 833-840. [CrossRef]

122. Chen, S.Y.; Wang, Y.; Telen, M.J.; Chi, J.T. The genomic analysis of erythrocyte microRNA expression in sickle cell diseases. PLoS ONE 2008, 3, e2360. [CrossRef] [PubMed]

123. Kannan, M.; Atreya, C. Differential profiling of human red blood cells during storage for 52 selected microRNAs. Transfusion 2010, 50, 1581-1588. [CrossRef] [PubMed]

124. Wang, K.; Yuan, Y.; Cho, J.H.; McClarty, S.; Baxter, D.; Galas, D.J. Comparing the MicroRNA spectrum between serum and plasma. PLoS ONE 2012, 7, e41561. [CrossRef] [PubMed]

125. Smith, L.; Shanthakumar, M.R.D. Final Evaluation Report of the Bowel Screening Pilot Screening Rounds One and Two; New Zealand Ministry of Health: Wellington, New Zealand, 2016.

126. Thery, C.; Witwer, K.W.; Aikawa, E.; Alcaraz, M.J.; Anderson, J.D.; Andriantsitohaina, R.; Antoniou, A.; Arab, T.; Archer, F.; Atkin-Smith, G.K.; et al. Minimal information for studies of extracellular vesicles 2018 (MISEV2018): A position statement of the International Society for Extracellular Vesicles and update of the MISEV2014 guidelines. J. Extracell. Vesicles 2018, 7, 1535750. [CrossRef] [PubMed]

(C) 2019 by the authors. Licensee MDPI, Basel, Switzerland. This article is an open access article distributed under the terms and conditions of the Creative Commons Attribution (CC BY) license (http://creativecommons.org/licenses/by/4.0/). 